\title{
Involvement of gicerin, a cell adhesion molecule, in the portal metastasis of rat colorectal adenocarcinoma cells
}

\author{
KAZUHIDE ADACHI ${ }^{1}$, MAHIRO HATTORI ${ }^{2}$, HIDENORI KATO $^{1}$, MARIE INAI ${ }^{1}$, MASAYA TSUKAMOTO $^{1}$, \\ EKOWATI HANDHARYANI ${ }^{4}$, EIICHI TAIRA ${ }^{3}$ and YASUHIRO TSUKAMOTO ${ }^{1}$ \\ ${ }^{1}$ Department of Animal Hygiene, Graduate School of Environmental and Biological Sciences, \\ Kyoto Prefecture University, Kyoto; ${ }^{2}$ Department of Veterinary Anatomy, Graduate School of \\ Environmental and Biological Sciences, Osaka Prefecture University, Osaka; ${ }^{3}$ Department of Pharmacology, \\ Graduate School of Medicine, Iwate Medical University, Iwate, Japan; ${ }^{4}$ Faculty of Veterinary Medicine, \\ Bogor Agriculture University, JL. Agatis, Kampus IPB Darmaga, Bogor 16680, Indonesia
}

Received June 8, 2010; Accepted July 9, 2010

DOI: 10.3892/or_00001002

\begin{abstract}
Gicerin, an Ig-superfamily cell adhesion molecule, has homophilic adhesion activity, thus leading to the formation of gicerin aggregates. Gicerin is highly expressed in various embryonic tissues, and it contributes to development through its adhesive activities. In contrast, the expression of the protein is limited to the muscular tissues and endothelial cells in the mature animals. In the liver, gicerin is constitutively expressed in sinusoidal endothelial cells. Interestingly, an overexpression of gicerin is found in a variety of tumors and may play a role in tumorigenesis. Previously, up-regulated expression of the gicerin protein was found in some sporadic cases of chicken colorectal adenocarcinomas and their hepatic metastasized lesions. In the present study, gicerin cDNA was introduced into endogenous gicerin negative ACL-15 cells, a rat colon adenocarcinoma cell line. The cells were subsequently evaluated for changes in their metastatic potentials in order to elucidate the possible role of gicerin in the hepatic metastasis of colorectal adenocarcinomas. The stable overexpression of gicerin in the cells enhanced the self-aggregation and migratory activities on the protein compared with the mock-transfectants. In addition, the gicerintransfectants had enhanced metastatic potential to the liver compared with mock-transfected cells after implantation into the ileocolic vein of the cognate rats. These results suggest that gicerin might promote the interaction of tumor cells with a hepatic endothelium, thus leading to the hepatic metastasis of colon adenocarcinomas.
\end{abstract}

Correspondence to: Professor Yasuhiro Tsukamoto, Department of Animal Hygiene, Graduate School of Biology and Environmental Sciences, Kyoto Prefecture University, 1-5 Nakaragicho, Shimogamo, Kyoto 606-8522, Japan

E-mail: ytsuka@kpu.ac.jp

Key words: gicerin, cell adhesion molecule, colorectal adenocarcinoma, metastasis, liver

\section{Introduction}

Gicerin is an immunoglobulin-superfamily cell adhesion molecule (CAM) purified from chicken smooth muscle as a neurite promote factor (1). The genomic sequence of gicerin is highly homologous with B-CAM, BEN/DM-GRASP/SC1, HEMCAM and CD146/MelCAM (2-4). Gicerin contains five Ig-like domain structures in the extracellular region. Each domain is rendered stable by a disulfide cross-link between two B-pleated sheets. The cytoplasmic domain is relatively short and it possesses potential recognition sites for protein kinases, although direct evidence of phosphorylation of these sites is still lacking. Chicken gicerin exhibits homophilic cell adhesion activity, in addition to the heterotypic adhesion to neurite outgrowth factor (NOF), a laminin-like molecule (5-7). However, this heterophilic binding activity of gicerin has not been observed in other animals. Gicerin appears in numerous embryonic tissues, including the nervous system, kidneys, and respiratory system, and seems to play a role in cell migration, neurite extension, epithelialization and cell condensation through its cell adhesive activity (8). Gicerin is almost completely absent from most adult tissues, and its expression is restricted to muscles and endothelial cells in blood vessels. Interestingly, we found gicerin to be overexpressed in some sporadic tumors of animals, including Wilm's tumor, oviductal adenocarcinomas, lymphatic sarcomas, melanoma, and mammary gland adenocarcinomas (9-12). In addition, we also previously showed gicerin transfection to promote the formation of gicerin aggregates, while increasing both migration and metastasis, as determined by in vitro analyses and cell implantation experiments using animals $(11,13)$.

Colorectal carcinomas are a suitable tumor to elucidate the potential function of gicerin on cancer metastasis with respect to the tumor-endothelial interactions for several reasons. First, colorectal carcinoma is a highly metastatic malignancy, and metastasizes most frequently to the liver through the portal vein. Second, several sporadic cases of colorectal carcinoma have been reported in animals, and the hepatic metastases of these tumors were enriched in gicerin 
in our preliminary study. Finally, hepatic sinusoidal endothelial cells constitutively express gicerin on its cell surface. We hypothesized that the introduction of the gicerin gene into gicerin-negative cells, and the subsequent analysis of their metastatic potential in the liver may thus provide a useful model for elucidating the possible role of gicerin in hepatic metastasis. In the present study, we established gicerin-transfected ACL cells, a transplantable cell line derived from a rat colorectal adenocarcinoma, and then examined the hepatic metastasis of these and control cells following implantation into the portal vein.

\section{Materials and methods}

Establishment of gicerin-expressing ACL cells by a gene introduction. The ACL-15 cells were cultured in dishes with Dulbecco's modified Eagle's medium (DMED) containing $10 \%$ fetal calf serum (FCS) at $37^{\circ} \mathrm{C}$. Semiconfluent cells were transfected with pcDNA 3.1 plasmid vector (Invitrogen) containing the intact rat gicerin gene. Control (mock-transfected) cells were transfected with the empty vector only. These transfectants were cultured in DMEM containing $10 \mu \mathrm{g}$ of G418 (Gibco), and then the resistant colonies were picked and grown. Each clone was examined for gicerin expression by immunocytochemistry and Western blot analysis. Finally, three stable gicerin-transfected clones (G1, G2 and G3) and three lines of mock-transfected cells (M1, M2 and M3) were established and used for further experiments.

Protein extractions and Western blotting. The transfected cells grown in DMEM were detached from the culture dish with a rubber scraper and then were centrifuged at 3,000 rpm for $10 \mathrm{~min}$. The collected cells were homogenized in PBS and centrifuged at 15,000 rpm for $15 \mathrm{~min}$. The pellet was solubilized by incubation in $10 \mathrm{mM}$ Tris/acetate $(\mathrm{pH} \mathrm{8.0)}$, $0.5 \mathrm{mM}$ EDTA, $0.5 \%$ Nonidet P-40 at room temperature for $1.5 \mathrm{~h}$ on a rotating shaker, then centrifuged at $15,000 \mathrm{rpm}$ for $20 \mathrm{~min}$. The resulting supernatants were used for Western blot experiments. Equal volume of the supernatants was separated using 7.5\% SDS-PAGE and electrotransferred to polyvinyl difluoride membranes (Bio-Rad). The blots were blocked with $3 \%$ skim-milk in PBS containing $0.05 \%$ Tween-20 (PBST) for $1 \mathrm{~h}$ at $37^{\circ} \mathrm{C}$ and then incubated with a primary antibody against gicerin diluted in PBST with $3 \%$ skim-milk for $1 \mathrm{~h}$ at $37^{\circ} \mathrm{C}$. After washing the membranes with PBST three times, they were incubated with the secondary antibody in PBST with 3\% skim milk for $1 \mathrm{~h}$ at $37^{\circ} \mathrm{C}$. Next, the membranes were washed three times in PBST and washed in PBS, and the blots were visualized on X-ray film using ECL solution (Gibco) (14).

Immunocytochemistry. Each of the transfected cell lines was grown on the cover slips to semiconfluency and then was fixed in Zamboni's fixative solution. The cover slips were washed twice with PBS and incubated with the polyclonal rabbit antibody against gicerin for $1 \mathrm{~h}$ at $37^{\circ} \mathrm{C}$ (13). After being washed twice with PBS, the cover slips were incubated with fluorescein isothiocyanate-conjugated goat anti-rabbit immunoglobulins (Dako) for $1 \mathrm{~h}$ at $37^{\circ} \mathrm{C}$. After being washed with PBS, the cover slips were examined under a fluorescent microscope.

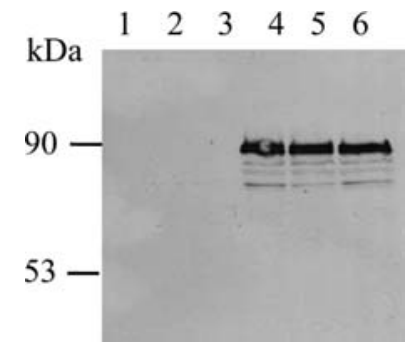

Figure 1. Expression of gicerin in the rat ACL colorectal adenocarcinoma cell line. Western blot analysis of gicerin protein expression in the membrane fractions from mock-transfected ACL cells (lane 1-3) and three lines of gicerin-transfected cells (lanes 4-6). Each lane was loaded with $20 \mu \mathrm{g}$ of membrane fractions from the cells. The number on the left panel indicates the molecular size of the protein in kilodaltons. Note that gicerin is expressed at around $90 \mathrm{kDa}$ in all three of the gicerin-transfeced cell lines.

Cell-aggregation assay. The monolayer cultures of parental cells and each of the transfected cell lines were digested with a solution of $0.05 \%$ trypsin and $0.01 \%$ EDTA and collected by centrifugation at $800 \mathrm{x} \mathrm{g}$, and then re-suspended in DMEM at $6 \times 10^{6}$ cells $/ \mathrm{ml}$. Cell suspension $(1 \mathrm{ml})$ was incubated in a round-bottomed polystyrene tube at $37^{\circ} \mathrm{C}$. After a 30-min incubation, the tubes were inverted once and a sample of $50 \mu 1$ was removed and observed under a microscope. To quantify aggregation, the number of cells present as single cells and in clusters ( $>4$ cells) was counted (at least 100 cells counted in total). The degree of cell aggregation was indicated by the index $\mathrm{N}_{30} / \mathrm{N}_{0}$, where $\mathrm{N}_{0}$ is the total cell number including aggregated clusters and $\mathrm{N}_{30}$ is only the aggregated cell cluster number. The experiment was performed five times, the scores were averaged, and then the standard deviations were calculated.

In vitro cell-migration assay. Polyvinylpyrrolidone-free polycarbonate filters $(5-\mu \mathrm{m}$ pore size) were coated with gicerin protein $(50 \mathrm{ng} / \mathrm{ml})$ and placed in modified Boydenchambers (Gibco) (12). A 200- $\mu 1$ aliquot of parental cells, mock- or gicerin-transfected cells $\left(2.0 \times 10^{6}\right.$ cells $\left./ \mathrm{ml}\right)$ was placed in the upper compartment of the Boyden-chambers. DMEM was placed in the lower compartment. After $8 \mathrm{~h}$ of incubation at $37^{\circ} \mathrm{C}$, the number of cells that had migrated into the lower compartment were counted under a microscope. The scores were averaged, and then the standard deviations were calculated.

Implantation of gicerin-transfected cells into the rat portal vein. The gicerin and mock-transfected cells (suspensions of $1.4 \times 10^{6}$ cells in $1 \mathrm{ml}$ DMEM) were injected into the ileocolic vein of adult male F344 rats (five animals for each transfected cell line). Gicerin transfectanted cells incubated with an anti-gicerin polyclonal antibody $(400 \mu \mathrm{g} / \mathrm{ml})$ for $2 \mathrm{~h}$ were also injected into the rats as a control. After 10 days, the rats were sacrificed under deep anesthesia with pentobarbital solution, and the lungs, liver, spleen and kidneys were removed and fixed with Zamboni's solution. The paraffin-embedded samples were cut into $3-\mu \mathrm{m}$ slices with a microtome, and stained with hematoxylin and eosin. The sections were then observed under a light microscope. The number of metastatic foci in the medial lobe of the liver was 

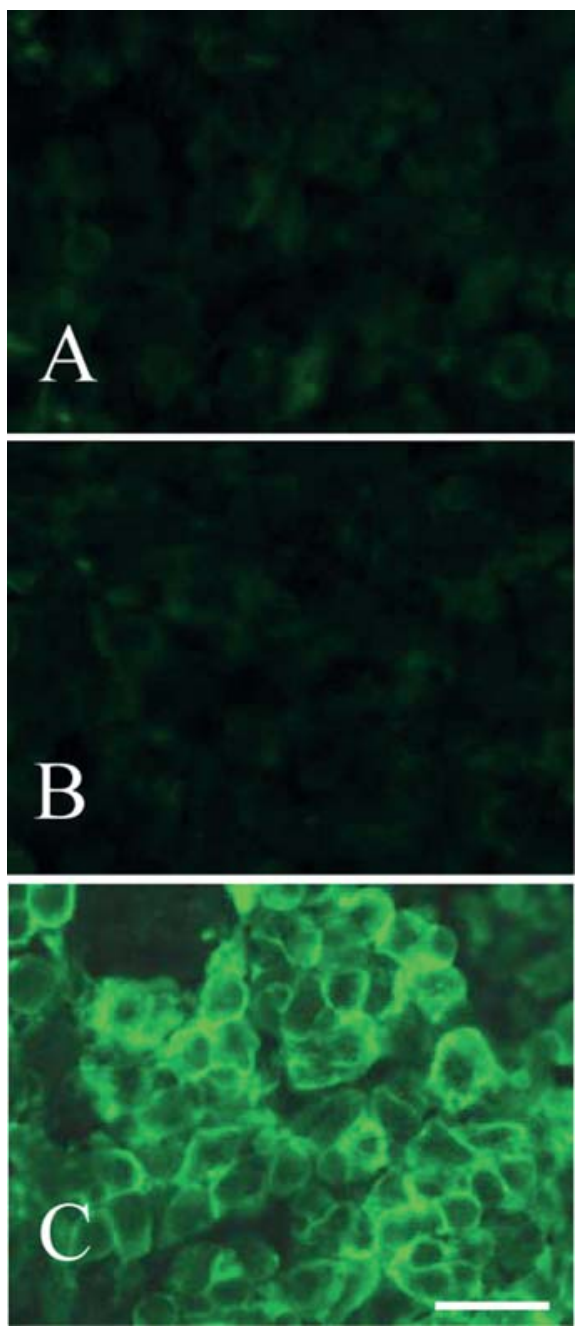

Figure 2. Immunocytochemical staining for gicerin in the gicerin-transfected cells. Gicerin is not expressed in the parental ACL (A) and mock cells (M1) (B). In contrast, gicerin is enriched on the cell surface of gicerin transfected cells (G1). Bars, $100 \mu \mathrm{m}$.

counted per $\mathrm{mm}^{2}$. The score were averaged in each of the rats injected with parental, mock- and gicerin-transfected cells, and standard deviations were calculated. The experiments were all approved by the animal care committee of Osaka Prefecture University.

\section{Results}

Cell aggregation and migration activities of gicerintransfected ACL-15 cells. The expression of gicerin in the ACL cells was examined by immunocytochemical and Western blot analyses using an anti-gicerin polyclonal antibody. This antibody detected bands of around $90 \mathrm{kDa}$ in the membrane fractions of all gicerin-transfected cells (G1, G2 and G3), but not in any of the three mock-transfected cell lines (Fig. 1). Gicerin was not expressed in either the parental cells or any of the mock-transfected cell lines, but was strongly expressed on the membrane of gicerintransfected cells (Fig. 2). All of the gicerin-transfected cells stably expressed gicerin on their cell surface even at further passages. Accordingly, we were able to establish ALC-cells that stably express gicerin.

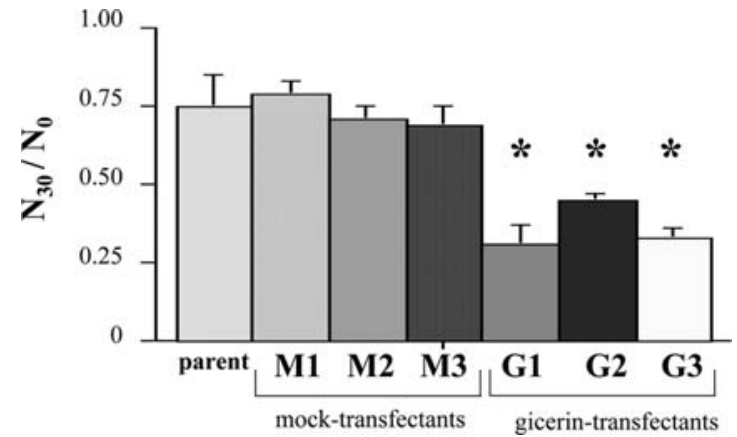

Figure 3. In vitro cell aggregation assay. Aliquots of parental cells, mock cells and gicerin-transfected cells were incubated for $30 \mathrm{~min}$ at $37^{\circ} \mathrm{C}$, and the particle number was counted in a hemocytometer. The degree of cell aggregates was estimated by the index $\mathrm{N}_{30} / \mathrm{N}_{0}$ (Materials and methods). Cell aggregation is indicated when the $\mathrm{N}_{30} / \mathrm{N}_{0}$ index is lower. Each point represents an average of four independent experiments. The results are reported as the means $\pm \mathrm{SD} .{ }^{*} \mathrm{P}<0.05$ compared with data from parental ACL cells (Student's t-test).

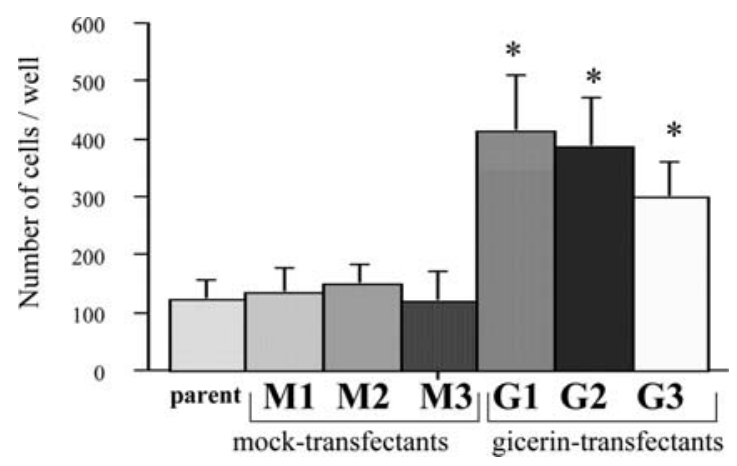

Figure 4. In vitro migration activity of gicerin-transfectants. Each of the parental-, mock- and gicerin-transfected cell lines were seeded onto transwell filters coated with gicerin protein. After an 8 -h incubation at $37^{\circ} \mathrm{C}$, the cells that had migrated to the lower compartment were counted under a microscope. The data were expressed as the average \pm SD of five experiments for each cell type. ${ }^{*} \mathrm{P}<0.05$ compared with data from parental cells on non-coated filters (Student's t-test).

An in vitro cell aggregation assay showed that all gicerin transfectants had enhanced self-aggregation, whereas parental and all of the mock-transfected cells showed only slight aggregation (Fig. 3). These findings indicate that the gicerin expressed by the transfected cells was functional with respect to the cell-cell interactions.

An in vitro cell migration assay showed a considerable number of the gicerin-transfected cells to migrate into the basement chambers through the pores of filters coated with the gicerin protein. The migration of these cells dramatically increased in comparison to the parental and mock-transfected cells (Fig. 4). Therefore, gicerin protein promoted the cell migration of gicerin-transfected cells due to their increased homophilic adhesion activity.

Hepatic metastasis of gicerin-transfected cells in F344 rats. Macroscopic metastasis was not detectable in any organ of rats implanted with any of the three types of cells (data not shown). However, we found that the transfection of gicerin altered the histopathology of the livers. A considerable number 

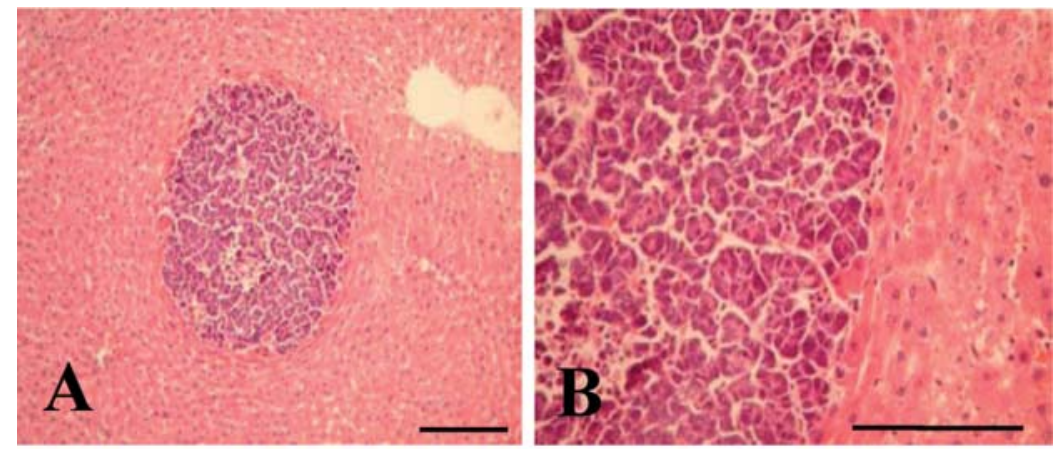

Figure 5. Hepatic metastasis of gicerin-transfected cells in F344 rats. Paraffin-embedded sections of rat liver engrafted with gicerin-transfected cells (G1) were cut and stained with H\&E. The presence of metastasis was found in the liver (A), with neoplastic tubular or acinar structures observable in the parenchyma (B). Bars, $200 \mu \mathrm{m}$.

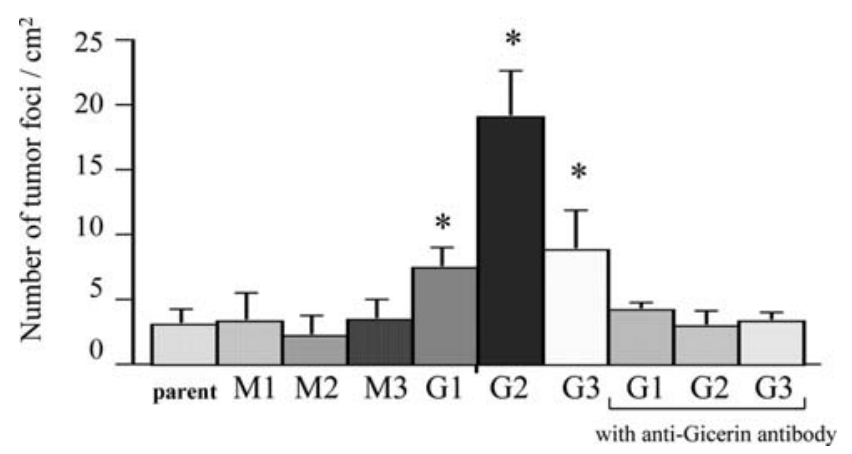

Figure 6. Metastatic activity of gicerin-transfected cells in F344 rats. The number of metastatic lesions in the medial lobe of the liver on day 10 postinjection for the parental, mock and gicerin-transfected cells in the portal vein were counted. The gicerin-transfected cells incubated with the antigicerin polyclonal antibody were also injected as a control. The number of foci was counted in an area of $1 \mathrm{~cm}^{2}$ using light microscopy. Each bar represents the mean $\pm \mathrm{SD}$ of five rats injected with each of the cell lines. ${ }^{*} \mathrm{P}<0.05$ compared with parental ACL cells (Student's t-test).

and various sizes of hepatic metastatic foci were found in the hepatic tissues after rats were injected with the gicerintransfected cells. Neoplastic tubular or acinar structures developed in the hepatic tissue of these rats (Fig. 5). The livers from the animals engrafted with parental and mocktransfected cells had only small number of small metastatic lesions, whereas the invasive metastasis was drastically increased in hepatic tissues following an injection with any of the three gicerin-transfected cell lines (Fig. 6). The antigicerin antibody inhibited the metastatic activity of all gicerintransfected cells. Accordingly, it was clear that the ACL cells obtained their high metastatic potential as a result of gicerin expression on the cell membrane, leading the enhanced portal metastasis. No other organs developed metastasis in any of the rats examined.

\section{Discussion}

In the present study, we established gicerin-expressing ACL-15 cells by transfecting gicerin cDNA into the parental ACL-15 cells. The gicerin protein on the surface of the transfected cells was functional in vitro with respect to cellcell binding. In addition, the transfected cells had an increased migratory activity as a result of homophilic (gicerin-gicerin) adhesion. One particularly interesting and potentially important finding in the present study was that gicerin could remarkably enhance the in vivo hepatic metastatic potential of ACL-15 cells. Since there were no obvious differences in doubling times among the established cell lines (data not shown), the enhanced metastasis of gicerin-transfected might have resulted from an increase in cell adhesion and migration, but not from the cell growth.

It is well known that in situ metastasis requires a multistep process characterized by a changing relationship between cancer cells and normal tissues: cancer cells must detach from the primary sites, intravasate through the neighboring cells and/or ECM-networks and then bind to the blood vessels and extravasate into the metastatic site(s) (15). The loss or dysfunction of E-cadherin is thought to be instrumental in releasing cells from a primary tumor mass byreducing contact-mediated regulation (16). On the other hand, overexpression of other CAMs encourages the migration of cells through the ECM (17). Gicerin interacts with itself, as well as with a laminin-like molecule, and probably with other unidentified protein (5). These adhesive activities of gicerin promote the in vitro migration of embryonic neural cells and primary oviductal cancer cells $(4,13,18,19)$. In addition, the expression of HEMCAM, which is the same molecule as gicerin, in mouse fibroblasts can down-regulate the maturation of $\beta-1$ integrins and decrease the integrin-dependent cell adhesion of laminin $\beta-1$, fibronectin and vitronectin (20). These gicerin-mediated cell adhesion activities might result in the enhancement of metastatic activity observed for the ACL-15 cells. Accordingly, the pathway underlying the increase in tumor invasion by gicerin seems to be quite complicated. We believe that gicerin-transfected cells have greater activity with regard to the processes of tumor metastasis, including cells intravasation, embolism and extravasation. In both normal and neoplastic tissues, gicerin is enriched in endothelial cells, and NOF is increased in the basement membrane. These distribution patterns of gicerin and its ligand suggest that gicerin-transfected cells can easily attach to the surface of endothelial cells by gicerin-gicerin binding, allowing the cells to embolize in the vessels. Subsequently, the promotion of cell invasion by gicerin-gicerin and/or gicerin-ECM interactions leads to extravasation through the vessel walls. 
The interaction of cell adhesion molecules with cytoskeletal elements is involved in a number of cellular functions, such as the ability to form junctions, cell mobility and the mediation of signal transduction $(21,22)$. In our other recent studies, gicerin was observed to be expressed on the microvilli of L-929 transfected cells, and it was firmly bound to actin filament through moesin, a member of the ERM family (23). Thus, the interaction of gicerin with actin filament might increase the mobility of cells.

In conclusion, we herein provided evidence that the expression of gicerin promotes the hepatic metastasis of ACL cells as a result of its increased homophilic adhesive activity. Recently, overexpression of gicerin was found in 10 cases of rat sporadic colorectal cancers: namely, gicerin appeared on the cell surface of cancer cells invading into the muscular layer and metastasizing in the liver. Therefore, gicerin might be involved in the malignant progression of sporadic cases, thereby confirming our observations using these cell lines. We are now examining the expression of gicerin on various types of sporadic tumors in humans, and examining its correlation with the stages of malignancy. We suspect that other molecular events are needed for the acquisition of the fully invasive and metastatic phenotype, although the expression of gicerin on tumor cells contributes to metastasis. Since the natural triggers of such molecular pathways remain unknown, it will be necessary to investigate whether the expression of gicerin is regulated by extracellular factors, such as growth factors and cytokines. The identification of the factors controlling gicerin transcription may thus enable us to inhibit the gicerin-dependent aspects of the malignant progression of cancers.

\section{Acknowledgements}

This study was supported in part by a Grant-in-Aid for Scientific Research from the Ministry of Education, Science, Sports and Culture, Japan (No. 21380182).

\section{References}

1. Taira E, Takaha $\mathrm{N}$ and Miki N: Extracellular matrix proteins with neurite promoting activity and their receptors. Neurosci Res 17: 1-8, 1993

2. Tanaka H, Matsui T, Agata A, Tomura M, Kubota I, McFarland KC, Kohr B, Lee A, Phillips HS and Shelton DL: Molecular cloning and expression of a novel adhesion molecule, SC1. Neuron 7: 535-545, 1991

3. Campbell IG, Folks WD, Seneger G, Troesdale J, GarinChesa P and Rettig WJ: Molecular cloning of the B-CAM cell surface glycoprotein of epithelial cancers: a novel member of the immunoglobulin superfamily. Cancer Res 54: 5761-5765, 1994.

4. Vainio O, Dunon D, Aissi F, Dangy JP, McNagny KM and Imhof BA: HEMCAM, an adhesion molecule expressed by c-kit ${ }^{+}$hemopoietic progenitors. J Cell Biol 135: 1655-1668, 1996.

5. Taira E, Takaha $\mathrm{N}$, Taniura $\mathrm{H}, \mathrm{Kim} \mathrm{CH}$ and Miki $\mathrm{N}$ : Molecular cloning and functional expression of gicerin, a novel cell adhesion molecule that binds to neurite outgrowth factor. Neuron 12: 861-872, 1994.
6. Taira E, Nagino T, Taniura H, Takaha N, Kim $\mathrm{CH}$, Kuo $\mathrm{CH}$ $\mathrm{Li}$ BS, Higuchi $\mathrm{H}$ and Miki $\mathrm{N}$ : Expression and functional analysis of a novel isoform of gicerin, an immunoglobulin superfamily cell adhesion molecule. J Biol Chem 270: 28681-28687, 1995.

7. Taira E, Nagino T, Tsukamoto Y, Okumura S, Muraoka O, Sakuma F and Miki N: Cytoplasmic domain is not essential for the cell adhesion activities of gicerin, an Ig superfamily molecule. Exp Cell Res 253: 697-703, 1999.

8. Tsukamoto Y, Taira E, Miki N and Sasaki F: The role of gicerin, a novel cell adhesion molecule, in development, regeneration and neoplasia. Histol Histopathol 16: 563-571, 2001.

9. Tsukamoto Y, Matsumoto T, Taira E, Kotani T, Yamate J, Takaha N, Tatesaki R, Namikawa T, Miki N and Sakuma S: Adhesive ability of gicerin, a cell adhesion molecule, in kidneys and nephroblastomas of chickens. Cell Tissue Res 292: 137-142, 1998.

10. Tsukamoto Y, Taira E, Kajimura K, Yamate J, Kotani T, Amin H, Kohama K, Sakuma S, Miki N and Sasaki F: Involvement of gicerin, a cell adhesion molecule, in development and regeneration of oviduct, and metastasis of oviductal adenocarcinomas of the chicken. Exp Cell Res 247: 329-338, 1999.

11. Tsukamoto Y, Sakaiuchi T, Hiroi S, Furuya M, Tsuchiya S, Sasaki F, Miki N and Taira E: Expression of gicerin enhances the invasive and metastatic activities of a mouse mammary carcinoma cell line. Int J Oncol 23: 1671-1678, 2003.

12. Tsuchiya S, Tsukamoto Y, Furuya M, Hiroi S, Miki N, Sasaki F and Taira E: Gicerin, a cell adhesion molecule, promotes the metastasis of lymphoma cells of the chicken. Cell Tissue Res 314: 389-397, 2003.

13. Tsukamoto Y, Egawa M, Hiroi S, Furuya M, Tsuchiya S, Sasaki F, Miki $\mathrm{N}$ and Taira E: Gicerin, an Ig-superfamily cell adhesion molecule, promotes the invasive and metastatic activities of a mouse fibroblast cell line. J Cell Physiol 197: 103-109, 2003.

14. Tsukamoto Y, Taira E, Kotani T, Yamate J, Wada S, Takaha N, Miki N and Sakuma S: Involvement of gicerin, a cell adhesion molecule, in tracheal development and regeneration. Cell Growth Differ 7: 1761-1767, 1996.

15. Cunningham BA: Cell adhesion molecules as morphoregulators. Curr Opin Cell Biol 7: 628-633, 1995.

16. Takeichi M: Cadherins in cancer; implications for invasion and metastasis. Curr Opini Cell Biol 5: 806-811, 1993

17. Albelda SM: Role of integrins and other cell adhesion molecules in tumor progression and metastasis. Lab Invest 68: 4-17, 1993.

18. Taira E, Tsukamoto Y, Kohama K, Maeda M, Kiyama H and Miki N: Expression and involvement of gicerin, a cell adhesion molecule, in the development of chick optic tectum. J Neurochem 88: 891-899, 2004.

19. Tsukamoto Y, Taira E, Yamate J, Nakane Y, Kajimura K, Tsudzuki M, Kiso Y, Kotani T, Miki N and Sakuma S: Gicerin, a cell adhesion molecule, participates in the histogenesis of retina. J Neurobiol 33: 769-780, 1997.

20. Alais S, Allioli N, Pujades C, Duband JL, Vainio O, Imhof BA and Dunon D: HEMCAM/CD146 downregulates cell surface expression of beta 1 integrins. J Cell Sci 114: 1847-1859, 2001.

21. Klymkowsky MW and Parr B: The body language of cells: the intimate connection between cell adhesion and behavior. Cell 83: 5-8, 1995.

22. Stein JV, Cheng G, Stockton BM, Fors BP, Butcher EC and Andrian UH: L-selectin-mediated leukocyte adhesion in vivo: microvillous distribution determines tethering efficiency, but not rolling velocity. J Exp Med 189: 37-49, 1999.

23. Okumura S, Muraoka O, Tanaka H, Tsukamoto Y, Kohama K, Miki N and Taira E: Involvement of gicerin in the extension of microvilli. Exp Cell Res 271: 269-276, 2001. 